\title{
La matière Congo
}

Pierre Leroux, Nicolas Martin-Granel et Claire Riffard

URL : http://journals.openedition.org/coma/566

DOI : $10.4000 /$ coma.566

ISSN : 2275-1742

\section{Éditeur}

Institut des textes \& manuscrits modernes (ITEM)

\section{Référence électronique}

Pierre Leroux, Nicolas Martin-Granel et Claire Riffard, «La matière Congo », Continents manuscrits [En ligne], 4 | 2015, mis en ligne le 16 mars 2015, consulté le 16 avril 2021. URL : http:// journals.openedition.org/coma/566 ; DOI : https://doi.org/10.4000/coma.566

Ce document a été généré automatiquement le 16 avril 2021

\section{(c) $(1) \Theta($}

Continents manuscrits - Génétique des textes littéraires - Afrique, Caraîbe, dispora est mis à disposition selon les termes de la licence Creative Commons Attribution - Pas d'Utilisation Commerciale - Pas de Modification 4.0 International. 


\title{
La matière Congo
}

\author{
Pierre Leroux, Nicolas Martin-Granel et Claire Riffard
}

1 Écrit avec un $\mathrm{K}$ ou un C, le Congo constitue « au cœur » de l'Afrique un lieu privilégié où un imaginaire plus ou moins mythifié s'est élaboré autour de quelques lieux ou de quelques traces. Écoulement du fleuve vers la mer, souvenir du Royaume Kongo, représentations du colon entre Stanley et de Brazza, voilà autant de motifs qui s'appuient sur un espace à géométrie variable et qui génèrent des écritures qui se réécrivent sans fin. Ce dossier est conçu comme un cheminement d'une version à l'autre - une approche génétique - ce qui n'empêche pas une circulation plus large, d'une œuvre à l'autre, dans une double perspective comparatiste et géopoétique.

Le Congo tel qu'il apparaît en littérature nous intéresse au premier chef car il constitue un lieu commun à plusieurs continents et à plusieurs époques qui donne lieu pourtant à des représentations très diverses. Mais le Congo imaginaire excède le champ de la littérature et nous avons intégré à ce dossier un article sur la bande-dessinée.

\section{AUTEURS}

\section{PIERRE LEROUX}

Doctorant, Paris III

NICOLAS MARTIN-GRANEL

Chercheur-associé, ITEM

CLAIRE RIFFARD

ITEM CNRS-ENS 